\title{
Impact of COVID-19 on Children: Indian Perspective and Concerns: Are we Sentient?
}

\author{
Malarkodi Senniyappan*, Shweta Garadi, Rupinder Deol
}

\section{Malarkodi Senniyappan*, Shweta Garadi, Rupinder Deol}

Department of Nursing, All India Institute of Medical Sciences, Rishikesh, Uttarakhand, INDIA.

\section{Correspondence}

Mrs. Malar Kodi S

Assistant Professor, Department of

Nursing, All India Institute of Medical

Sciences, Rishikesh, Uttarakhand,

INDIA.

Phone no: +91-753380333

Email: malar.nur@aiimsrishikesh.edu.in

\section{History}

- Submission Date: 08-05-2021

- Revised Date: 01-05-2021

- Accepted Date: 10-07-2021

DOI : 10.5530/ijmedph.2021.4.33

Article Available online

http://www.ijmedph.org/v11/i4

\section{Copyright}

(C) 2021 Phcog.Net. This is an openaccess article distributed under the terms of the Creative Commons Attribution 4.0 International license.

\section{ABSTRACT}

COVID-19 has rattled our world, with devastating impact on children and families. Parents and children have been faced with new and evolving sources of stress in protecting them from the virus. The Novel COVID -19 pandemic situations have an impact in many ways on children. This article is an attempt to throw light on the impact of the COVID 19 pandemic among children and enumerates certain strategies to overcome it.

Key words: Children, COVID-19 infection, Impact, Pandemic, Perspectives, Concerns.

\section{INTRODUCTION}

The pandemic strike of COVID-19 infection has caused substantial changes in the lives of people over the past few months. Deleterious effects of this pandemic can be seen on millions of human beings including a larger group of children. Children being another vulnerable group and biggest victims of this attack may have changes in their lives in profound ways especially in those of lower socioeconomic group. More significantly this pandemic attack is impacting the overall development of children including nutrition, physical health, mental health, family economic growth, cognitive learning, safety at home, social development, protection, and creativity of these little kids. Nevertheless, these effects may be life-altering and destructive for few children.

Pediatric population was much less affected initially, exhibiting much fewer symptoms than the adult population however, the number of cases are growing among children. Data suggests that $8.5 \%$ of total reported cases were belonging to less than 18 years of age, relatively with mild disease and lower death rates compared to other age groups. ${ }^{1}$ The reason behind the lesser prevalence of COVID-19 among the pediatric population is still unclear. However, few children had a critical illness and most of the death cases had pre-existing medical conditions as in adults. One of the studies found that the clinical course of COVID-19 in children appeared to be less severe than in adults, also the study concluded saying co morbidities existed in many children who were affected with COVID-19. ${ }^{2}$

A study done by Foster et al. in 2020 on 57 pediatric patients with COVID-19 during the initial phase of the outbreak of this pandemic concluded that $83 \%$ presented with a fever or cough, and all those required admissions to the hospital had co morbidities including diabetic ketoacidosis, vaso-occlusive crisis,

acute chest syndrome, asthma exacerbation, altered mental status from hypernatremia, reactive arthritis, or appendicitis. ${ }^{3}$

In India, despite relatively low rates and varied evidence, it is a growing concern that children and adolescents be protected from COVID-19 as they constitute a large proportion of the population. Lockdown measures that were forced in the initial onslaught of the pandemic have affected children and adolescents' health and well-being, their learning, and the economic security of their families. This article aims to discuss the positive and negative impacts of the COVID-19 pandemic on Indian children and their life circumstances.

\section{IMPACT OF COVID-19 ON CHILDREN}

\section{POSITIVE IMPACT}

\section{- Childhood development}

School closures during the lockdown period affected children's education very badly. Thus, UNESCO has promoted learning solutions for children at a distance through digital teaching aids. Children who have access to these aids will be allowed to learn educational methods that will benefit them later in life. Involvement in online learning and creative activities during school closures will help them to develop new skills. The Economic Survey 2020-21 presented by the Union Minster for Finance and Corporate Affairs in the Annual Status of Education Report (ASER) stated that the percentage of children owning a smart phone has shown a good rise from 36.5 percent in 2018 to 61.8 percent in rural India. Several initiatives has been implemented by the Indian government for the easy accessibility of education during pandemic such as PM eVIDYA, Swayam MOOCs, Samagra

Cite this article : Senniyappan M, Garadi S, Deol R. Impact of COVID-19 on Children: Indian Perspective and Concerns: Are we Sentient. Int J Med Public Health. 2021;11(4):179-82. 
Shiksha Scheme, PRAGYATA and MANODARPAN. The report of survey showed a total 77.7 percent of literacy rate among individuals of 7 years and above age group and also stated that elementary school literacy level has reached to 96 percent. $^{4}$

\section{- Ideal social behavior}

Family being the best place to develop patience and resilience among children, parents have a greater role in supporting and motivating them. Though they were confined to their rooms and homes for a long period, facing the harshest restrictions not to meet their friend's circle, they still made an effort to understand the logic and reason behind it and coped up with the parent's suggestions. They showed an ideal social behavior of not shaking hands and greeting others with folding their hands and saying Namaste and also maintaining an appropriate social distance whenever it is needed.

\section{- $\quad$ Adaptive behavioral changes}

For the past many months, children have gained enough understating of hand hygiene and cough etiquette. Children started following all the precautionary measures in day-to-day life so keenly to prevent the spread of infection demonstrating their role as responsible citizens of the country. This indicates the great work of the family to create a safer and pleasant area to nurture their better development during this pandemic by encouraging the children to inculcate COVID appropriate behavior.

\section{- Innovation to stay connected}

This lockdown helped children to think innovatively with new ideas, interests, tips, and tricks to connect with their friends and siblings in newer ways. Children expressed their hidden talents unfolding them every day though initially, the boredom within four walls was triggering their aggressiveness. They could share their ideas, new knowledge, and interesting concepts learned with their close ones to reduce the stress level. Getting indulged in indoor physical activities, learning new educational skills lead to building up self-confidence and personality development in children. Even greater awareness about health and an unknown disease assists children to build the inner strength to tackle up such challenges in the future.

\section{- Developing relationships and empathy}

Spending time with the family members could help children to develop closer relationships and bonding with them. The impact of pandemic could also help children to develop more humanity and empathy, as they realized the value of human life. The COVID-19 lockdown period has brought the children closer to family, forming a bond of love and affection with the loved ones around. Inculcating to dwell on virtues of empathy and humanity in earlier stages of life helps children to build new horizons in developing relationships beyond the schools and home. Thus, children have begun to learn nature's values by caring for and valuing them. There is a shred of evidence concluding that this has led to a change of our natural environment that provided more opportunities for children to enjoy nature.

\section{NEGATIVE IMPACT}

An additional 6.7 million children could suffer from wasting due to the socioeconomic impacts of COVID-19. 1.5 billion Children have been out of school - leading to an education crisis.370 million children have missed out on free school meals. 80 million children under one could be at risk of other diseases, due to disruption in immunization programs. Worldwide, 142 million children are living in monetary-poor households, 150 million children living in multidimensional poverty and 463 million school children among the 500 million child population cannot reach digital and broadcast remote learning programs. ${ }^{5}$ The pandemic crisis has impacted children widely as follows:

\section{- Effects on education}

Globally, greater than 80 percent of children felt that they were learning a lot less than before. According to UNESCO, the learning of greater than
1.6 billion learners in over 190 countries has got disrupted. ${ }^{6}$ A significant number of parents and caregivers reported their child had received no contact from teachers since their schools closed during an initial lockdown. Closing facilities like libraries and schools will have an impact on children's education in several ways as they are the only way some children can access the internet. Around 1.5 million schools are closed in India during pandemic and switched to digital education which was benefited by $24 \%$ in urban and $4 \%$ in rural households only as reported by government survey. And the budget for digital learning was crashed down from Rs. 469 crore to 604 crore in 2020-21. ${ }^{7}$ Lancker and Parolin in their study specified that being out of school also can be a primary risk of causing inequalities in education. ${ }^{8}$ The learning from digital education in various socioeconomic backgrounds due to school closures during lockdown had a considerable gap. This creates a crisis in learning among the poorest communities where internet speeds are considerably low. This also may cause a burden to families to afford necessary electronic gadgets like android devices and broadband services with an existing low income during the pandemic.

Many students were anxious and nervous to know about their future with cancelled or postponed examinations. Thus, the children's vocational life to be near started may certainly have an impact on it.

\section{- Health issues}

Children during lockdown had to cut down their physical activity as compared to their previous normal rates since they didn't have access to outdoor activities. Thus, there is an expectation of raised consequences of physical inactivity likely, weight gain, obesity, and associated disorders. Apart from this, health care accessibility has become tough and there was considerable deterioration in routine health care services. One of the studies highlighted that many children along with their caregivers were made to wait in the same isolation areas until the COVID-19 test report comes since there were no separate isolation areas available for children, which might have led to unnecessary exposure of infection. ${ }^{9}$ Children are at risk not only of infection but also of losing or being separated from family members and caregivers. Constrained access to clinics, schools, social workers, lack of child protection, and broader social services is particularly harmful to women and children in need of safety. Another study concluded that there was a higher incidence rate of disease among lower socioeconomic group people. ${ }^{10}$ Children are also at risk of acquiring posttraumatic stress after exposure to COVID-19 infection.

\section{- $\quad$ Reduced vaccine rate}

Already updating children with vaccination rates was an issue before the pandemic and the COVID -19 pandemic crisis aggravated this situation worse. Outreach activities for immunizations have been reduced due to social distancing, restrictions in intra and interstate travel and pandemic lockdown issues. As per the statistics of vaccination by UNICEF, it is estimated that 20-22 lakh children less than 1 year of age are targeted to receive their vaccinations every month in India. ${ }^{11}$ But, fear and stigma of COVID-19 infections in the parent's minds have made them miss the vaccinations for their children. ${ }^{12}$

\section{- Physical/Mental strain}

School closures might have also brought that children sit continuously for longer periods in front of television and computers which could lead to physical issues like back pain, eye strain, and disturbed sleep. The Hindu has reported a sudden spike in child abuse rates of $50 \%$ high during the lockdown, seeking protection against abuse and sexual violence. ${ }^{12}$

\section{- Lower immunity}

Children residing in underdeveloped countries especially those living in slums, immigration detention centers, orphanages, and other institutions may also face higher infection rates. These children living in areas 
with constrained access to proper health care facilities likely to spread the virus to other populations.

\section{- Behavioral changes}

Children miss their interaction with their peers and are deprived of being in close company with friends and kin which induces a lot of behavioural changes in them. Closure of schools, parks, and playgrounds have increased screen time for children at home which might give chance to mushrooming of many other complications such as mental health issues and lack of physical activity. Underprivileged children developed hunger issues and might have become severely undernourished too. ${ }^{13}$ Being isolated, living within physical distance from most wanted ones, and loneliness are challenging situations for every human being. A study from China found that children's ADHD behaviors significantly worsened during the COVID-19 outbreak in comparison with their normal state of living before the pandemic has arrived. A survey among Chinese schoolaged children during lockdown revealed higher rates of anxiety and depression than usual..$^{14}$

\section{- Lack of competitive environment}

Schools provide a vast platform to bring up the obscure talent and creativity among children. It helps the children to grow holistically teaching them to adapt to diverse environments and also to improve social connections. During the pandemic, Viner et al. carried out a rapid systematic review of 16 papers concluded saying that the personal and psychological growth of children can be hampered because of school closures..$^{15}$ Another study by Hinduja and Patchin during the pandemic, well said that children are exposed to a risk of cyber bullying owing to increased use of social media. ${ }^{16}$ The dangers of being online can also include inappropriate content for the age of child, filthy conversations, getting addicted to various harmful substances, which may lead to stress, anxiety, and even suicidal thoughts and attempts.

\section{- Increased risk of child exploitation}

UNESCO has suggested that this will have a devastating impact on children from low socioeconomic communities. ${ }^{17}$ Moreover, major issues among the population can be due to widespread job losses and greater economic insecurity, indirectly that may increase child labour rates, domestic violence, unfair treatment of children, females, and other vulnerable groups of the population. The children could even become abandoned or orphaned by losing their family members.

Census 2011 data suggests that the total number of child laborers in India is 4.35 million (main workers) between 5-14 years of age and 5.76 million (marginal workers) a total of 10.11 million. On a count ahead, the total number of adolescent laborers in India is 22.87 million, bringing the total (in the age group of 5-18 years) to around 33 million. ${ }^{18}$ The ongoing pandemic has multiplied the existing causes of child labor, as well as added new ones too.

\section{IMPACT ON CHILDREN WITH SPECIAL NEEDS}

Armitage and Nellums have stated that the COVID-19 response must consider children with disabilities and their needs too. ${ }^{19}$ These children are least likely to take benefits from distance learning options. Social distancing may act as an obstacle for the children with disabilities by interrupting in approach to regular face-to-face services in various contexts such as nutrition, therapy sessions, review visits to hospitals, access to health care, or personal care areas. This may further trigger many other consequences like behavioural changes, physical health issues and could even harm disabled children. Children with special needs can be given an option to access the therapy through an online platform for home-based care programs. But, parents who are not exposed to such virtual care experiences may find it inconvenient and impersonal to adapt. ${ }^{20} \mathrm{~A}$ study speaks about the long-term break-in physiotherapy for needy children may worsen the existing musculoskeletal and orthopedic functioning. Children with lesser attention capacities take a much longer time to inculcate health-related changes like hand sanitization, cough hygiene, and other standard respiratory etiquettes. ${ }^{21}$

The report of the largest and comprehensive survey conducted by the Save the Children program obtained for 46 countries for 13,477 children had key findings in many areas. It is reported that only $78 \%$ of children with disabilities attended school before COVID-19 whereas $90 \%$ in children without disabilities. 1 in 3 children's parents had reported their child had no access to any learning materials. An even smaller proportion of children with disabilities had friends during COVID-19 and a higher proportion of children were playing less and sleeping less too. Positive parenting methods of children with disabilities had shown a rise but simultaneously negative parenting methods in children without disabilities. Comparatively, a higher proportion of children with disabilities have shown increased negative feelings, signs of distress, and violence at home. ${ }^{22}$

\section{STRATEGIES TO OVERCOME}

Due to fear of the spread of COVID-19 infection, parents are dealing with the toughest task of holding up their children at home and develop a sense of calmness among them. From job loss to supply shortages, Parents are concerned about not only the physical health of children and but their emotional and mental health as well. As parents are involved in work from home, they equally are trying to maintain the safety of their children by providing stimulating activities.

Proper Nutrition and supplements: Good balanced, nutrient-rich diet helps a child to gain appropriate cognitive development at any age. This on another hand improves the academic performance of the child and gives a greater sense of achievement to the child. Keep children well-nourished and allow them to have adequate exposure to sunlight to prevent Vitamin D deficiency which has a prime role in the prevention of respiratory tract infections.

Physical activity and recess: A study by Chen et al. highlighted the need for physical activity regularly. They started regular physical activity during COVID - 19 pandemic at a safer home environment is like a boost for healthy living. But, children always should be given activities or tasks 15 to 20 min only with regular recess time. They need built-in breaks for a fresh air walk or sit out before they restart another task.

Seek help from teachers: Teachers though away from regular meetings with students can still play an important role in fulfilling children's needs through remote learning and assisting parents at home. The little ones may feel no sense in this online and digital learning. So, parents can listen to them patiently and empathize with their feelings. Parents can ask teachers for preferred communication methods for their children and offer thanks to teachers for helping better their children at this time.

Counseling and support: This is the most concerning area during a pandemic for children as they rely on parents for emotional and physical support. Analyze, through what situation is child passing through and make a way to get out of challenging issues by addressing them regularly. Use the right method to talk, reassure and deliver support to a child.

Prevention of infection and safe health: The child should be assessed for symptoms at regular intervals without any negligence even for the mildest symptoms. Regular practice of hand hygiene, social distancing from friends, neighbors, and playmates, screening of child in case of suspicious symptoms and exposure to infection and maintain safe health is nevertheless an important action to be considered by parents.

\section{Parental guidance}

World Health Organization and UNICEF have given evidence-based tips for better parenting especially during this pandemic in worldwide languages. These include one-on-one time with new ideas, to keep things 
positive as much as possible, structuring up the things between their schedules, how to deal with child's misbehavior, training them to keep calm, to talk and discuss COVID 19 with children, maintaining harmony at home and among family members, family budgeting in times of stress, how to overcome anger, keeping children safe while using a digital platform and social media, parenting tips teens, new baby, children with disabilities and parenting while staying in crowded homes or communities. ${ }^{23}$

\section{CONCLUSION}

Globally, the COVID-19 pandemic will have a long-term impact on children but the situation depends on the early stage of disease progression including several global, socio-economic and political factors. Though some of these are positive, other negative impacts will be pernicious and could affect a huge number of children in various ways. Children learn from parents or elders by looking at them for guidance to feel safe, cared for, and to stay healthy. Thus, parents and family members can help them to understand the situation to live a new normal by creating an appropriate sense of control around them without panicking and by taking necessary actions to reduce the spread of illness. They can aid the children by providing an opportunity for being creative and processing new information and innovative learning by considering this pandemic as a challenge. Teach them healthy hygienic measures to be free from infection, keep them occupied in schoolwork or learning activities and alleviate their fears.

Indian scenario is more painful to look into than other countries around the world. The existing social system is not so strong enough to control the worst storm of pandemic thus; negative impacts are visible. ${ }^{24}$ UNICEF is mobilizing rapid research shreds of evidence to scale up the situation. International organizations and child welfare institutions should work collaboratively to tackle the negative impacts on children as well as to prioritize funding and support for education, water, sanitization, and health-related measures during this pandemic. A robust community health approach network is needed to fulfill the essential care services to the children during this time.

\section{CONFLICT OF INTEREST}

The authors declare that there is no conflict of interest.

\section{REFERENCES}

1. Coronavirus disease (COVID-19): schools [internet]; 2021. Who.int [cited May 31 2021]. Available from: https://www.who.int/news-room/q-a-detail/coronavirusdisease-covid-19-schools.

2. Banerjee S, Guha A, Das A, Nandi M, Mondal R. A Preliminary Report of COVID-19 in Children in India. Indian Pediatr. 2020;57(10):963-4. doi: 10.1007/ s13312-020-2004-6.

3. Foster C, Moulton E, Munoz F, Hulten K, Versalovic J, Dunn J et al. Coronavirus disease; 2019. In: Children cared for at Texas Children's Hospital: initial clinical characteristics and outcomes [internet]. 2021 [cited May 31 2021]. Available from: https://doi.org/10.1093/jpids/piaa072

4. Online schooling has taken off in a big way during COVID-19 pandemic. Econ Surv. 2020-2021.
5. This is how COVID-19 is affecting the world's children [Internet] [cited May 31 2021]. Available from: https://www.weforum.org/agenda/2020/09/charts-covid19malnutrition-educaion-mental-health-children-world/. World Econ Forum; 2021.

6. internet; 2021. Available from: Un.org [cited May 31 2021]. Available from: https:// www.un.org/development/desa/dspd/wp-content/uploads/sites/22/2020/08/ sg_policy_brief_covid-19_and_education_august_2020.pdf

7. Covid-19 fallout. impact on education in India [internet]; 2021. MSN [cited May 31 2021]. Available from: https://www.msn.com/en-in/news/other/covid-19-fallout-the-impact-on-education-in-india/ar-BB1cqenl.

8. Van Lancker WV, Parolin Z. COVID-19, School closures, and child poverty: a social crisis in the making. Lancet Public Health. 2020:5(5):e243-4. doi: 10.1016/ S2468-2667(20)30084-0, PMID 32275858.

9. Juneja M, Gupta A. Managing children with special needs in COVID-19 times Indian Pediatr. 2020 October 15;57(10):971. doi: 10.1007/s13312-020-2009-1, PMID 32710532.

10. Choudhary B, Goyal JP. Management concern for non-COVID children during the COVID-19 pandemic. Indian Pediatr. 2020 June 15;57(6):591. doi: 10.1007/ s13312-020-1874-y, PMID 32366727.

11. Vaccination and immunization statistics - UNICEF DATA [internet]; 2021. UNICEF Data [cited May 31 2021]. Available from: https://data.unicef.org/topic/ child-health/immunization/.

12. Naseri A, Hosseini MS. Do not neglect the children: considerations for COVID-19 pandemic. Indian Pediatr. 2020 June 15;57(6):583-4. doi: 10.1007/ s13312-020-1868-9, PMID 32336686.

13. Sarangi B, Reddy VS, Oswal JS, Malshe N, Patil A, Chakraborty M, Lalwani S. Epidemiological and clinical characteristics of COVID-19 in Indian children in the initial phase of the pandemic. Indian Pediatr. 2020 October 15;57(10):914-7. doi: 10.1007/s13312-020-1994-4, PMID 32729850.

14. Kulkarni RK, Kinikar AA, Chandanwale A. Impact of COVID-19 on children and pediatricians. Indian Pediatr. 2020 May 15;57(5):480-1. doi: 10.1007/s13312-0201833-7 [Epub:480-1]. PMID 32273488.

15. Viner RM, Russell SJ, Croker H, Packer J, Ward J, Stansfield C, Mytton O, Bonell C, Booy R. School closure and management practices during coronavirus outbreaks including COVID-19: a rapid systematic review [internet]. Lance Child Adolesc Health. 2020;4(5):397-404. doi: 10.1016/S2352-4642(20)30095-X, PMID 32272089.

16. Patchin JW, Hinduja S. Bullies move beyond the schoolyard: A preliminary look at Cyberbullying. Youth Violence Juv Justice. 2006;4(2):148-69. doi: 10.1177/1541204006286288.

17. En, unesco.org. 2021 [citedMay312021].Availablefrom:https://en.unesco.org/sites/ default/files/gem2020-extraordinary-session-background-document-en.pdf

18. FACT. SHEET: child labour in India [internet]; 2021. Ilo.org [cited May 31 2021]. Available from: https://www.ilo.org/newdelhi/whatwedo/publications/ WCMS_557089.

19. Armitage R, Nellums LB. The COVID-19 response must be disability inclusive. Lancet Public Health. 2020 May;5(5):e257. doi: 10.1016/S2468-2667(20)30076-1. PMID 32224295, PMCID PMC7270835

20. Alsohime F, Temsah MH, Al-Nemri AM, Somily AM, Al-Subaie S. COVID-19 infection prevalence in pediatric population: etiology, clinical presentation, and outcome. J Infect Public Health. 2020 December;13(12):1791-6. doi: 10.1016/j. jiph.2020.10.008, PMID 33127335.

21. Jain $S$, Sen $S$, Lakshmivenkateshiah $S$, Bobhate $P$ Venkatesh $S$, Udani $S$ Shobhavat L, Andankar P, Karande T, Kulkarni S. Multisystem inflammatory syndrome in children with COVID-19 in Mumbai, India. Indian Pediatr. 2020 November 15;57(11):1015-9. doi: 10.1007/s13312-020-2026-0. PMID 32788432

22. Global programs [internet]. Save the Children; 2021 [cited May 31 2021]. Available from: https://www.savethechildren.org/us/what-we-do/global-programs.

23. Coronavirus (COVID-19) parenting tips. Vol. 2021. Available from-; 2020. Cited on 5Jan. Available from: https://www.unicef.org/coronavirus/COVID-19-parentingtips [cited 19/7/2021]

24. Karunathilake K. Positive and negative impacts of COVID-19, an analysis with special reference to challenges on the supply chain in South Asian countries. J Soc Econ Dev. 2020. doi: 10.1007/s40847-020-00107-z. 